\title{
The Relationship of Weight-adjusted Bone Mass Content Associated with COPD and Associated Factors
}

\author{
J. CHINDAPRASIRT ${ }^{1}$, W. BOONSAWAT ${ }^{2}$, P. LIMPAWATTANA ${ }^{3 *}$, D. THEERAKULPISUT ${ }^{4}$, M. MANJAVONG ${ }^{3}$, \\ K. SAWANYAWISUTH ${ }^{5}$, V. CHOTMONGKOL ${ }^{6}$, P. INTHASUWAN ${ }^{1}$, S. PUTRAVEEPHONG ${ }^{1}$ \\ ${ }^{1}$ Division of Oncology Medicine, ${ }^{2}$ Division of Respiratory system, ${ }^{3}$ Division of Geriatric Medicine, Department of Internal \\ Medicine, ${ }^{4}$ Division of Nuclear Medicine, Department of Radiology, ${ }^{5}$ Division of Ambulatory Medicine, ${ }^{6}$ Division of Neurology, \\ Department of Internal Medicine, Faculty of Medicine, Khon Kaen University, Thailand
}

Chindaprasirt et al.: Bone mass content in COPD

\begin{abstract}
The objectives of this study were to determine the distributions of weight-adjusted bone mass content and osteoporosis in chronic obstructive pulmonary disease patients, to examine the prevalence of osteoporosis and osteopenia and to determine factors associated with weight-adjusted bone mass content. A crosssectional study of chronic obstructive pulmonary disease patients at a tertiary-care hospital, Thailand was conducted from May 2015 to December 2016. Baseline characteristics were collected and bone mineral density and weight-adjusted bone mass content were measured using dual-energy $\mathrm{X}$-ray absorptiometry. A total of 107 chronic obstructive pulmonary disease patients were included. The prevalence of osteoporosis and osteopenia were 35.5 and $38.2 \%$, respectively. The distribution of weight-adjusted bone mass content of arms, legs and whole body was significantly correlated with chronic obstructive pulmonary disease severity $(\mathbf{p}<\mathbf{0 . 0 5})$, but not with the presence of osteoporosis. Factors associated with weight-adjusted bone mass content of the extremities was the severity of chronic obstructive pulmonary disease (adjusted odds ratios of moderate and severe chronic obstructive pulmonary disease were 1.03 and 1.06), waist circumference (adjusted odds ratio 0.99) and appendicular skeletal mass index (adjusted odds ratio 0.98). Both osteoporosis and osteopenia were present in more than a third of the chronic obstructive pulmonary disease patients. The weight-adjusted bone mass content of arms, legs, extremities and whole body were correlated with the degree of airflow limitation but not the presence of osteoporosis. Factors associated with weight-adjusted bone mass content of the extremities were identified. Weight-adjusted bone mass content could be a good index to indicate the degree of bone loss in chronic obstructive pulmonary disease patients.
\end{abstract}

Key words: Bone mass content, chronic lung disease, osteopenia, osteoporosis

Chronic obstructive pulmonary disease (COPD) is a common, preventable and treatable disease that is known mainly to affect the structure and function of the lungs. It is characterized by persistent respiratory symptoms and airflow limitation due to airway and/or alveolar abnormalities, usually caused by significant exposure to noxious particles or gases ${ }^{[1]}$. It is a major cause of morbidity and premature death and is the third leading cause of death worldwide ${ }^{[2]}$. According to a systematic analysis for the Global Burden of Disease Study conducted in 2015, the prevalence of COPD increased by $44.2 \%$ from 1990-2015 and there were 3.2 million people who died from COPD globally in 2015 with an increase of $11.6 \%$ compared to $1990^{[3]}$. Furthermore, COPD is a systemic disease that is complicated by numerous comorbidities and syndromes including lung cancer, atherosclerosis, weight loss and nutritional abnormalities, sarcopenia, frailty syndrome, hormonal and metabolic disturbances, osteoporosis, anxiety and depression ${ }^{[4-6]}$. Therefore, management of COPD should be directed toward identifying and treating those systemic effects, in addition to focusing on airway limitations, in order to improve health outcomes in COPD patients ${ }^{[6]}$.

Osteoporosis is one of the systemic effects of COPD, though the causal relationship and molecular association between COPD and osteoporosis has yet to be established ${ }^{[4]}$. It is commonly found in COPD patients and its prevalence is higher in these patients than in healthy subjects and those with various other 
chronic lung diseases such as asthma, idiopathic pulmonary fibrosis, pulmonary hypertension, sarcoidosis, scleroderma or Kartagener's syndrome and bronchiectasis $^{[7-11] .}$ Osteoporosis is also more prevalent in women than in $\operatorname{men}^{[11]}$. Moreover, forced expiratory volume in one second (FEV1 \% predict), body mass index (BMI) and free fat mass index (FFMI) have been found to be lower in osteoporotic COPD patients ${ }^{[1]}$. The reported prevalence of osteoporosis and osteopenia in COPD patients have varied from 8.7 to $69 \%$ and 18.6 to $67 \%$, respectively ${ }^{[4,6,7,10-17]}$. Osteoporosis can lead an increased risk of fracture, worsen pulmonary function and impair the activities of daily living in COPD patients. Therefore, the concurrence of COPD and osteoporosis could lead to a vicious cycle, causing a substantial burden to the patients ${ }^{[4,13]}$. COPD-related risk factors for osteoporosis include low body weight, smoking, age, gender, inactivity, systemic inflammation, pulmonary dysfunction, systemic corticosteroids, and vitamin D deficiency or insufficiency ${ }^{[13,14]}$.

Routine screening and management for osteoporosis in COPD patients enables physicians to diagnose this disorder at an early phase to reduce its negative consequences. However, some studies only have found the degree of reduced bone mineral density (BMD) to be comparable to the severity of airflow limitation ${ }^{[7-10]}$, meaning that measurement of BMD might not be a good index or sensitive enough tool to determine the degree of bone loss in COPD patients. Additionally, there have been few studies conducted in Thailand regarding the prevalence of osteoporosis and osteopenia and their association with COPD severity. One study reported that the prevalence's of osteoporosis and osteopenia were 31.4 and $32.4 \%$, respectively and that they were not associated with severity of COPD ${ }^{[16]}$. Measurement of bone mass content that included parts of the body other than the femoral neck and lumbar spine like BMD might be helpful. One report showed that bone mass content index (BMCI), which is derived from bone mass content/height ${ }^{2}$, was lower in the legs, trunk and overall in COPD patients than in control subjects. The BMCI of the trunk was associated with $\mathrm{VO}_{2}$ max and BMI, but not with airflow limitation. BMI, which includes body weight, appears to be more closely related to bone mass content than height alone. Therefore, the purpose of this study was to determine the distribution of weightadjusted bone mass content (w-BMC) and osteoporosis in male patients with COPD by COPD severity. This study also aimed to examine the prevalence of osteoporosis and osteopenia and factors that affect $\mathrm{w}-\mathrm{BMC}$.

\section{Subjects and setting:}

This was a sub-study of several previously published articles ${ }^{[5,18]}$. A cross-sectional study of COPD patients was conducted at the Srinagarind Hospital COPD clinic at Khon Kaen University's Faculty of Medicine, Thailand from May 2015 to December 2016. The clinic is a tertiary care referral center at the university hospital to which patients are sent from the internal medicine outpatient clinic and other community hospitals. The inclusion criteria were, male sex, Thai citizenship, COPD, age over $18 \mathrm{y}$ and attendance at the Srinagarind Hospital COPD clinic. Subjects were excluded if they had other active illnesses such as functional class III-IV heart failure, pneumonia or septicemia, those who had experienced COPD exacerbation within the preceding $4 \mathrm{w}$, those who were unable to complete the study due to physical limitations such as being bed ridden or suffering from hemiparalysis, those who were unwilling to participate in the study, those who were limited in their ability to undergo dual energy X-ray absorptiometry (DXA) or had conditions that would affect DXA results, those who had taken barium or had had an enema within the previous $2 \mathrm{w}$, those who had metallic instrumentation such as a vertebral fixation device, had undergone a radionuclide scan within the previous $2 \mathrm{w}$, or had body weight over 200 $\mathrm{kg}$ exceeding the capacity of the DXA. Subjects with incomplete body composition data were also excluded.

\section{Definition:}

COPD was diagnosed in subjects according to the criteria laid out by the Global Initiative for Chronic Obstructive Lung Disease (GOLD): persistent airflow limitation and a post-bronchodilator force expiratory volume in one second (FEV1) less than $70 \%$ of forced vital capacity (FVC). Severity of COPD was based on the GOLD staging system, which consists of 4 levels, mild (FEV1> $80 \%$ normal), moderate (FEV1 50 $-79 \%$ normal), severe (FEV1 30-49\% normal) and very severe $(\mathrm{FEV} 1<30 \% \text { normal })^{[1]}$.

The MMRC scale was used to evaluate dyspnea in daily life. The patients were asked to rate their dyspnea on a scale of 0-4 for various physical activities that can provoke the condition as follows: 0 , not troubled with breathlessness except with strenuous exercise; 1 , troubled by shortness of breath when hurrying on the level or walking up a slight hill; 2, walks slower than people of the same age on the level because of 
breathlessness or has to stop for breath when walking at own pace on the level; 3 , stops for breath after walking about 100 yards or after a few min on the level; and 4, too breathless to leave the house, or breathless when dressing or undressing ${ }^{[19]}$.

DXA (General Electric Lunar-Progidy) was used to estimate bone mass and skeletal muscle mass in patients diagnosed with osteoporosis whose T-scores of the femoral neck or lumbar spine were $<-2.5$ standard deviation ${ }^{[20]}$. Weight-adjusted bone mass content (w-BMC) was calculated as bone mass content/weight ${ }^{2}$ $\left(\mathrm{g} / \mathrm{kg}^{2}\right)$. Appendicular skeletal muscle mass index (ASMI) was calculated as appendicular skeletal mass/ height $^{2}\left(\mathrm{~kg} / \mathrm{m}^{2}\right)^{[21]}$.

Handgrip strength $(\mathrm{kg})$ was measured using a handheld dynamometer (GRIP-D Model: T.K.K.5401). The patients were asked to hold the handgrip dynamometer in one hand with the arm at a right angle and the elbow by the side of the body. When ready, the patients squeezed the dynamometer with maximum isometric effort, which was maintained for about $5 \mathrm{~s}$. Three attempts were measured and the maximal measurement was recorded $^{[22]}$. The patient's 6 min walk distance (6MWD) was used to measure physical performance according to the American Thoracic Society guidelines ${ }^{[23]}$. Gait speed $(\mathrm{m} / \mathrm{s})$ was then analyzed based on 6MWD.

\section{Procedure:}

Potential subjects were asked by the team of researchers to participate in this study at the COPD clinic. They were informed of the research purpose, protocol, risks and benefits of enrolling. After those who met the inclusion criteria and were willing to participate in the study gave informed consent, their baseline information was collected by trained clinical researchers. The demographic data collected included age, sex, educational level, smoking status, severity of COPD using the most recent pulmonary function test results (within the past $6 \mathrm{mo}$ ), MMRC score, comorbid diseases, regular medication use, history of falls over the previous $12 \mathrm{mo}$, self-reported baseline function with regard to basic and instrumental activities of daily living (ADL) using the Barthel ADL index and Chula index ${ }^{[24]}$, history of non-elective admission over the previous $12 \mathrm{mo}$, weight, height, waist circumference and systolic and diastolic blood pressure at rest. Weight and height were used to calculate BMI. Waist circumference (WC) was measured after exhalation midway between the lower rib and the iliac crest. Systolic and diastolic blood pressure was presented as mean arterial blood pressure (MAP). Handgrip strength was measured using a grip dynamometer ${ }^{[22]}$, and 6MWD (as previously described) was used to measure physical performance ${ }^{[21,24]}$. DXA was used to measure body composition including muscle mass, bone mineral density and bone mass content. All measurements were performed on all patients during the same period. The main purpose of DXA is to measure BMD. Using spectral imaging but not the body composition, perhaps DXA may be used to measure body composition only to a certain extent in a few cases.

\section{Statistical analysis:}

Baseline data were analyzed using descriptive statistics and were presented as percentage, mean and standard deviation (SD). If the distributions of these data were not normal, then median and inter-quartile range were used instead. The Chi-squared test/Fisher's exact test was used to compare the proportions of patients with and without osteoporosis between the COPD patients. Differences in w-BMC by COPD severity were determined using a one-way analysis of variance. A p-value $<0.05$ indicated statistical significance. Effects of factors associated with w-BMC of the extremities were evaluated using univariate and stepwise multivariate linear regression analyses with logistic transformation. In terms of univariate analysis, crude odds ratio (ORs) and $95 \%$ confidence intervals (CIs) were used to determine the strength of association of the factors examined with w-BMC of the extremities. Factors with a $p$-value of $<0.20$ or that were found to have clinical significance in previous studies were then entered into a multiple linear regression model. A p-value of $<0.05$ was considered to indicate statistically significant differences and adjusted OR (AOR) and $95 \%$ CIs were used to determine the strength of association. All data analysis was carried out using STATA version10.0 (StataCorp, College Station, Texas). Ethical approval was provided by the Khon Kaen University Faculty of Medicine Ethics Committee as instituted by the Helsinki Declaration (Number HE581060).

\section{RESULTS AND DISCUSSION}

Patient characteristics are presented in Table 1. Of the 109 subjects evaluated, 2 were excluded because of incomplete body composition data, which left 107 patients to be enrolled in this study. The mean age was $69.7 \mathrm{y}$. The majority of the patients had moderate COPD (59.8\%), and inhaled corticosteroids were the most commonly used medication $(94.4 \%)$. Most of the subjects were independent with regard to activities of 
daily living. Osteoporosis was found in about a third $(35.5 \%)$ of the subjects.

The distribution of osteoporosis in patients with COPD by severity is shown in fig. 1 . The prevalence of osteoporosis did not differ significantly with COPD severity, while the w-BMC of the arms, legs, extremities, and overall did ( $\mathrm{p}<0.05)$, as shown in fig. 2 .

w-BMC of the extremities was used as an index of bone loss among COPD patients in this study because w-BMC of the arms, legs, extremities and overall differed significantly by level of COPD severity (fig. 2), which implied that w-BMC of the arms and legs were important regions in predicting bone loss. Thus, $\mathrm{w}-\mathrm{BMC}$ of the extremities was used to analyze the associations of other factors. Severity of COPD, presence of diabetes, WC, MAP, ASMI, and handgrip strength were associated with w-BMC of the extremities according to univariate analysis as shown in Table 2. After multicollinearity was confirmed, factors with a $p<0.2$ according to univariate analysis and those previously reported to be clinically significant (including age, smoking status, severity of COPD, MMRC, presence of DM, dyslipidemia, chronic arthritis, regular use of inhaled or systemic steroids, NSAIDs, and statin, fall history, MAP, ASMI, waist circumference, and handgrip strength) were entered into the model for multivariate analysis. These factors were then entered in the stepwise multiple regression models with logistic transformation. Greater severity of COPD, decreased WC and decreased ASMI were factors associated with increased w-BMC in this study (Table 2).

The prevalence of osteoporosis and osteopenia among male patients with COPD in this study were 35.5 and $38.2 \%$, respectively, which is in line with the findings of previous studies, in which these prevalence ranged from 8.7-69 \% and 18.6-67\%, respectively ${ }^{[4,6,7,10-17]}$. Variations in prevalence among studies might be attributable to methodological differences in the assessment of BMD and differences in the characteristics of study populations such as age, sex, ethnicity, severity of COPD and past use of bone medications. Another study conducted in Thai COPD patients found that $31.4 \%$ had osteoporosis and $32.4 \%$ had osteopenia, similar to the findings of this study ${ }^{[16]}$. The high prevalence of these conditions in COPD patients highlights the importance of early recognition of the risk factors and implementation of strategies to manage osteoporosis in these patients in order to prevent adverse health outcomes such as osteoporotic fracture and poor quality of life ${ }^{[7]}$. However, this study
TABLE 1: BASELINE CHARACTERISTICS OF THE STUDIED POPULATION

\begin{tabular}{|c|c|}
\hline Variables & $\mathrm{N}=107$ \\
\hline Age $(\mathrm{y})$, mean $(\mathrm{SD})$ & $69.7(9.1)$ \\
\hline $\begin{array}{l}\text { Age }(y), n(\%) \\
-<65 y\end{array}$ & $29(27.1)$ \\
\hline$-65-74 y$ & $43(40.2)$ \\
\hline$->75 y$ & $35(32.7)$ \\
\hline $\begin{array}{l}\text { Educational level, } \mathrm{n}(\%) \\
-6 \text { y or less }\end{array}$ & $50(46.7)$ \\
\hline$-7-12$ y & $26(24.3)$ \\
\hline$->12 y$ & $31(29.0)$ \\
\hline Current smoker, n (\%) & $8(7.5)$ \\
\hline $\begin{array}{l}\text { Severity of COPD, n (\%) } \\
\text { - Mild }\end{array}$ & $26(24.3)$ \\
\hline - Moderate & $64(59.8)$ \\
\hline - Severe & $16(15.0)$ \\
\hline - Very severe & $1(0.9)$ \\
\hline MMRC score, mean (SD) & $0.7(1.1)$ \\
\hline $\begin{array}{l}\text { Comorbid diseases, n (\%) } \\
\text { - Diabetes mellitus }\end{array}$ & $12(11.2)$ \\
\hline - Hypertension & $39(36.5)$ \\
\hline - Dyslipidemia & $10(9.4)$ \\
\hline - Chronic arthritis & $9(8.4)$ \\
\hline - Cancer & $6(5.6)$ \\
\hline $\begin{array}{l}\text { Regular medication, n (\%) } \\
\text { - Inhaled steroids }\end{array}$ & $101(94.4)$ \\
\hline - Systemic steroids & $2(1.9)$ \\
\hline - Oral hypoglycemic drugs & $6(5.6)$ \\
\hline - Statin & $11(10.3)$ \\
\hline - NSAIDs & $1(0.9)$ \\
\hline $\begin{array}{l}\text { Two or more falls over the past } 1 \mathrm{y} \text {, } \\
\mathrm{n}(\%)\end{array}$ & $3(2.8)$ \\
\hline Barthel scores, mean (SD) & $19.91 .1)$ \\
\hline Chula iADLs scores, mean (SD) & $9(0.2)$ \\
\hline $\begin{array}{l}\text { Non-elective admission over the past } \\
1 \mathrm{y}, \mathrm{n}(\%)\end{array}$ & $28(26.2)$ \\
\hline BMI (kg/m2), mean (SD) & $23.2(4.0)$ \\
\hline WC (cm), mean (SD) & $89.611 .4)$ \\
\hline MAP (mm Hg), mean (SD) & $96.1(10.8)$ \\
\hline $\begin{array}{l}\text { Appendicular skeletal mass index } \\
\left(\mathrm{kg} / \mathrm{m}^{2}\right) \text {, mean }(\mathrm{SD})\end{array}$ & $7.2(0.9)$ \\
\hline 6MWD $(\mathrm{m})$, mean (SD) & $426.3(76.2)$ \\
\hline Gait speed $(\mathrm{m} / \mathrm{s})$, mean $(\mathrm{SD})$ & $1.2(0.2)$ \\
\hline Handgrip strength $(\mathrm{kg})$, mean (SD) & $26.95 .9)$ \\
\hline Osteopenia, n (\%) & $41(38.2)$ \\
\hline Osteoporosis, n (\%) & 38 (35.5) \\
\hline w-BMC (g/ $\left.\mathrm{kg}^{2}\right)$, mean (SD)-Arms & $0.1(0.03)$ \\
\hline - Legs & $0.25(0.08)$ \\
\hline - Extremities & $0.34(0.11)$ \\
\hline - Trunk & $0.18(0.05)$ \\
\hline - Whole body & $0.65(0.20)$ \\
\hline \multicolumn{2}{|c|}{$\begin{array}{l}\text { NSAIDs- non-steroidal antiinflammatory drugs, iADL- instrumental } \\
\text { activities of daily living, BMI- body mass index, WC- waist circumference, } \\
\text { MAP- mean arterial blood pressure, osteoporosis is defined as a femoral } \\
\text { neck or lumbar spine T-score of } 2.5 \text { SD or more below the mean for young } \\
\text { adults, osteopenia is defined as a femoral neck or lumbar spine T-score of } \\
\text { between } 1.0 \text { and } 2.5 \text { SD below the young adult mean, appendicular skeletal } \\
\text { mass is calculated by summing the muscle masses of the } 4 \text { limbs, } 6 \mathrm{MWD}- \\
\text { 6-minute walk distance, MMRC scale- Modified Medical Research Council } \\
\text { scale, w-BMC- weight adjusted bone mass content = bone mass content }(\mathrm{g}) / \\
\text { weight }(\mathrm{kg})^{2}\end{array}$} \\
\hline
\end{tabular}


www.ijpsonline.com

TABLE 2: UNIVARIATE AND STEPWISE MULTIVARIATE LINEAR REGRESSION ANALYSES

\begin{tabular}{|c|c|c|c|c|c|c|}
\hline \multirow[t]{2}{*}{ Factors } & \multicolumn{3}{|c|}{ Univariate analysis } & \multicolumn{3}{|c|}{ Multivariate analysis } \\
\hline & Crude OR & $(95 \% \mathrm{Cl})$ & $\mathrm{p}$-value & Adjusted OR & $(95 \% \mathrm{Cl})$ & $\mathrm{p}$-value \\
\hline Age & 1.00 & $(0.99,1.001)$ & 0.09 & & & \\
\hline \multicolumn{7}{|l|}{ Educational level } \\
\hline . 6 years or lower & 1 & - & - & & & \\
\hline . $7-12$ years & 0.98 & $(0.94,1.04)$ & 0.72 & & & \\
\hline$\cdot>12$ years & 0.99 & $(0.93,1.03)$ & 0.34 & & & \\
\hline Current smoker & 0.96 & $(0.89,1.04)$ & 0.31 & & & \\
\hline \multicolumn{7}{|l|}{ Severity of COPD } \\
\hline - Mild & 1 & - & - & 1 & - & - \\
\hline - Moderate & 1.01 & $(0.97,1.06)$ & 0.56 & 1.03 & $(1.003,1.05)$ & $0.03^{*}$ \\
\hline - Severe & 1.1 & $(1.04,1.17)$ & $0.003^{*}$ & 1.06 & $(1.02,1.09)$ & $0.003^{*}$ \\
\hline - Very severe & 1.35 & $(1.11,1.65)$ & $0.003^{*}$ & 1.15 & $(1.03,1.28)$ & $0.02^{*}$ \\
\hline MMRC & 1.02 & $(0.99,1.04)$ & 0.05 & 1.01 & $(0.99,1.02)$ & 0.19 \\
\hline Diabetes mellitus & 0.94 & $(0.88,0.99)$ & $0.04^{*}$ & & & \\
\hline Hypertension & 0.98 & $(0.93,1.02)$ & 0.24 & & & \\
\hline Dyslipidemia & 0.94 & $(088,1.01)$ & 0.11 & & & \\
\hline Chronic arthritis & 0.94 & $(0.87,1.01)$ & 0.09 & & & \\
\hline Cancer & 1.03 & $(0.94,1.13)$ & 0.48 & & & \\
\hline \multicolumn{7}{|l|}{ Regular medication } \\
\hline - Inhaled corticosteroids & 0.96 & $(0.87,1.04)$ & 0.31 & & & \\
\hline - Systemic steroids & 1 & $(0.86,1.16)$ & 0.99 & 0.93 & $(0.86,1.0 .1)$ & 0.06 \\
\hline - Oral hypoglycemic drugs & 0.97 & $(0.88,1.06)$ & 0.45 & & & \\
\hline - Statin & 0.95 & $(0.86,1.01)$ & 0.1 & 0.93 & $(0.94,1.01)$ & 0.2 \\
\hline - NSAIDs & 0.86 & $(0.70,1.07)$ & 0.17 & & & \\
\hline Two or more falls over the past 12 months & 1.02 & $(0.89,1.15)$ & 0.78 & & & \\
\hline Barthel scores & 1 & $(0.98,1.02)$ & 0.73 & & & \\
\hline Chula iADLs scores & 1.04 & $(0.93,1.15)$ & 0.47 & & & \\
\hline WC $(\mathrm{cm})$ & 0.992 & $(0.991,0.993)$ & $0.00^{*}$ & 0.993 & $(0.992,0.994)$ & $0.00^{*}$ \\
\hline $\begin{array}{l}\text { Non-elective admission over the past } 12 \\
\text { months }\end{array}$ & 1.04 & $(0.99,1.08)$ & 0.09 & & & \\
\hline MAP & 0.997 & $(0.995,0.999)$ & $0.01^{*}$ & & & \\
\hline Appendicular skeletal mass index $\left(\mathrm{kg} / \mathrm{m}^{2}\right)$ & 0.92 & $(0.91,0.94)$ & $0.00^{*}$ & 0.98 & $(0.97,0.99)$ & $0.04^{*}$ \\
\hline Gait speed $(\mathrm{m} / \mathrm{s})$ & 0.99 & $(0.89,1.09)$ & 0.84 & & & \\
\hline Handgrip strength $(\mathrm{kg})$ & 0.993 & $(0.991,0.996)$ & $0.00^{*}$ & 0.99 & $(0.99,1.00)$ & 0.14 \\
\hline
\end{tabular}

Univariate and stepwise multivariate linear regression analyses with logistic transformation of factors associated with $\mathrm{w}$-adjusted BMC of the extremities. ${ }^{*} \mathrm{p}$-value $<0.05$ indicated significance, $\mathrm{Cl}$ - confidence interval, OR- odds ratio. Factors with a $\mathrm{p}<0.2$ according to univariate analysis and factors previously reported to be clinically significant (age, inhaled corticosteroids, systemic steroids) were entered into the model for multivariate analysis.

could not demonstrate the relationship between severity of COPD and the occurrence of osteoporosis found by a study conducted in Italy ${ }^{[9]}$ among others ${ }^{[7,15]}$. This is partly due to the small number of patients in our study with greater COPD severity.

Rampant use of corticosteroids through inhalational, systemic routes appeared to have blocked the absorption of calcium into systemic circulation eventually causing decrease in the BMD, health of the soft muscle tissues. One interesting finding of this study was the distribution of the $\mathrm{w}-\mathrm{BMC}\left(\mathrm{g} / \mathrm{cm}^{2}\right)$ in the arms, legs, extremities and whole body in COPD patients, which demonstrated that higher w-BMC was significantly related to greater severity of COPD. Thus, this index might be used to predict the severity of bone loss in patients with COPD with greater accuracy than the presence of osteoporosis, which is based on the BMD of the femoral neck or lumbar spine. A possible explanation for this association is the connection between body weight and BMC found in several previous studies ${ }^{[9,25-27]}$. Low body weight might be associated with lower calcium intake, protein malnutrition, 


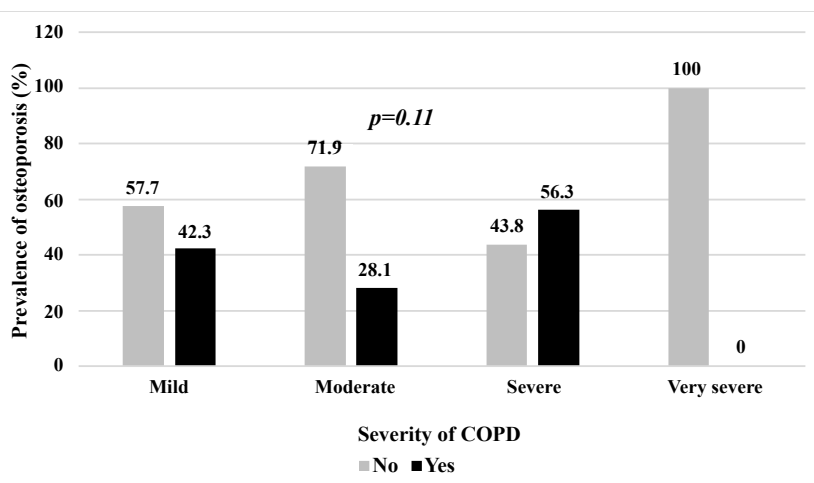

Fig. 1: The distribution of osteoporosis (\%) in patients with COPD by COPD severity

$\mathbf{P}<\mathbf{0 . 0 5}$ were considered to indicate significance. No- no osteoporosis, Yes- presence of osteoporosis, osteoporosis is defined as a femoral neck or lumbar spine T-score of 2.5 standard deviation or more below the young adult mean

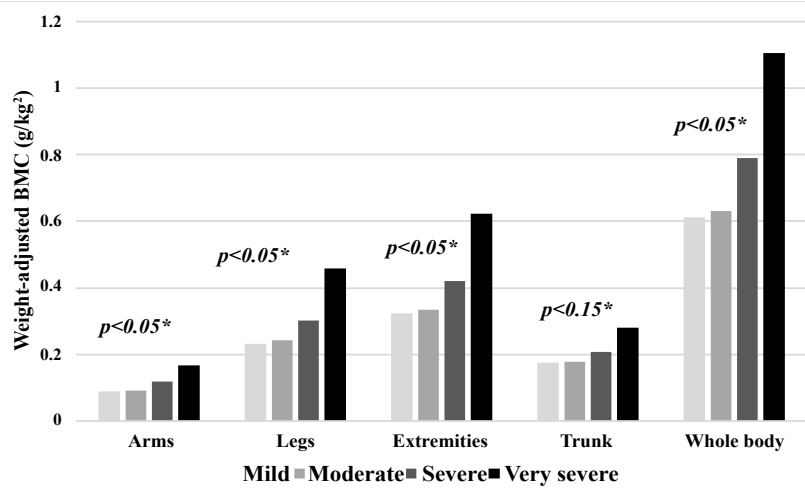

Fig. 2: The distribution of the weight adjusted bone mass content The distribution of the $\mathrm{w}-\mathrm{BMC}\left(\mathrm{g} / \mathrm{cm}^{2}\right)$ in the arms, legs, extremities, trunk and whole body in COPD patients by COPD severity $* P<0.05$ were considered to indicate significance

immobilization, and corticosteroid administration and it can affect the biomechanical stress placed on bones ${ }^{[26,27]}$. Body weight must thus be considered when examining changes in $\mathrm{BMC}^{[26]}$. Furthermore, body weight is likely to decline to a greater degree than the bone mass in COPD patients ${ }^{[9]}$, meaning that higher $\mathrm{w}-\mathrm{BMC}$ is associated with greater severity of airflow limitation. A prior report also showed that there was no significant association between height-adjusted BMC and severity of $\mathrm{COPD}^{[25]}$, which suggests that height is not a suitable as a parameter to examine changes in BMC. In our study, only w-BMC of the trunk was not significantly related with severity of COPD. This can be explained by the mechanism of BMC preservation in the mechanical stress on the bones like trunk. COPD patients tend to have higher metabolic and ventilatory requirements and dyspnea than non-COPD patients, so the bone mass content in the trunk is inclined to remain stable while the limitations to physical activity, such as walking and standing, in patients with severe COPD leads to less mechanical stress on the bones, resulting in significant changes in the $\mathrm{w}-\mathrm{BMC}$ of the arms, legs, and overall[ ${ }^{[25]}$.

Independent factors associated with high $\mathrm{w}-\mathrm{BMC}$ of the extremities in this study were greater severity of COPD, decreased WC, and ASMI. The association between $\mathrm{w}-\mathrm{BMC}$ and COPD severity may be explained by the bone loss and decreases in body weight that result from a greater degree of airflow limitation. However, body weight is reduced to a greater degree than bone mass in these cases, as mentioned earlier ${ }^{[9,25-27]}$, meaning that the proportion of bone mass content to body weight ${ }^{2}$ tends to be higher in more severe cases ${ }^{[6,9,25]}$. Decreased WC is another factor that was related to high w-BMC, which was a marker of bone loss in COPD patients in this study. This confirms that WC is positively associated with bone mass ${ }^{[28]}$ and supports a prior finding that WC is a key determinant of bone mass ${ }^{[29]}$. However, this relationship has been found to hold only up to a certain body size threshold and not to be significant in subjects with WCs of $100-110 \mathrm{~cm}$ or greater ${ }^{[28,29]}$. The mean WC of the subjects in this study was below this threshold, at $89.6 \mathrm{~cm}$, indicating that there should be a significant correlation between WC and bone mass in this population. Generally, WC is an indicator of abdominal obesity, which represented visceral adipose tissue ${ }^{[29,30]}$, and several reports have found this surrogate measure to be associated with low bone mass and increased risk of hip fracture when body mass index was taken into account ${ }^{[29,31,32]}$. This implies that both abdominal obesity and lower waist circumference are associated with bone mass loss. Decreases in ASMI have also been shown to be independently associated with w-BMC. The results presented here support the oppositional relationship between lean mass and bone mass $\operatorname{loss}^{[28]}$. In men, increases in bone and muscle mass result from greater levels of testosterone and IGF-1 ${ }^{[33]}$. In patients with COPD, there are additional cofactors that exacerbate the decline of skeletal mass and bone including (1) physical inactivity due to exercise intolerance, (2) systemic inflammation causing excessive apoptosis of skeletal muscle and increased inflammatory cytokines, such as tumor necrosis factor alpha and IL-6, which contribute to the regulation of bone remodeling, and (3) the possible presence of hypoxia and use of systemic steroids $^{[13,18,33,34]}$.

As osteoporosis is also common in COPD patients and results in various unfavourable health outcomes, early prevention and treatment is crucial. However, this study found that a diagnosis of osteoporosis based on femoral or lumbar bone mineral density was not 
related to severity of COPD and that w-BMC had several advantages over the traditional diagnosis of osteoporosis as an indicator of bone loss. First, it correlated to the severity of airflow limitation. Second, it includes bone mass content of all extremities, where the traditional method includes only the femoral neck and lumbar spine. Third, it is adjusted by body weight, the effect of which on the occurrence of osteoporosis and COPD is supported by an abundance of data.

There were some limitations to this study. First, the number in the group with COPD severity stage "Very severe" is small, further study with higher number of subjects should be conduct. Second, the subjects were all Asian men, so the result might not be representative of women or other racial or ethnic groups, as these factors can influence bone mineral density ${ }^{[2,35]}$. Third, some known factors that are associated with osteoporosis were not measured such as physical activity and vitamin D levels. Last, this study was conducted in a tertiary care hospital, and the subjects may have had more comorbidities or greater severity of disease than those in a community hospital setting. Therefore, the prevalence of osteoporosis and osteopenia found in this study might not be generalizable to other settings. Further research in various study populations is required.

The prevalence of osteoporosis and osteopenia was high in male patients with COPD. The traditional diagnosis of osteoporosis was not related to the severity of airflow limitation, where w-BMC of the arms, legs, extremities, and whole body was. Factors associated with w-BMC of the extremities were the severity of COPD, WC, and ASMI. We recommend using w-BMC of the extremities to indicate degree of bone loss as a part of routine COPD management. Further studies are required to investigate the optimal w-BMC cut-off point that is related to adverse health outcomes.

\section{Funding:}

This study was funded by the Neuroscience Research and Development Group (Khon Kaen University, Thailand).

\section{Conflict of interest:}

All authors have no conflicts of interest with respect to the authorship.

\section{Acknowledgements:}

We would like to thank Dr. Dylan Southard (Research Affairs, Faculty of Medicine, Khon Kaen University,
Thailand) for editing the manuscript. The authors also would like to thank Sleep Apnea Research Group (Khon Kaen University, Thailand).

\section{Authors' contributions:}

Dr Jarin Chindaprasirt contributed to the study design, concept of this work, interpretation of data, and approval for final version of the article. Dr Watchara Boonsawat, Dr Daris Theerakulpisut, Dr Manchumad Manjavong, Prof. Kittisak Sawanyawisuth, and Prof. Verajit Chotmongkol contributed to the concept of this study and approval for the final version of the article. Dr Pratchaya Inthasuwan and Dr Siraphong Putraveephong contributed to acquisition of data. Dr Panita Limpawattana contributed to the study design, analysis and interpretation of data, writing drafted manuscript and approval the version to be published. All authors have read and approved the manuscript.

\section{REFERENCES}

1. Vogelmeier CF, Criner GJ, Martinez FJ, Anzueto A, Barnes PJ, Bourbeau J, et al. Global Strategy for the Diagnosis, Management, and Prevention of Chronic Obstructive Lung Disease 2017 Report. GOLD Executive Summary. Am J Respir Crit Care Med 2017;195:557-82.

2. Quaderi SA, Hurst JR. The unmet global burden of COPD. Glob Health Epidemiol Genom 2018;3:e4.

3. Soriano JB, Abajobir AA, Abate KH, Abera SF, Agrawal A, Ahmed MB, et al. Chronic Respiratory Disease Collaborators. Global, regional, and national deaths, prevalence, disabilityadjusted life years, and years lived with disability for chronic obstructive pulmonary disease and asthma, 1990-2015: a systematic analysis for the Global Burden of Disease Study 2015. Lancet Respir Med 2017;5:691-706.

4. Inoue D, Watanabe R, Okazaki R. COPD and osteoporosis: links, risks, and treatment challenges. Int J Chron Obstruct Pulmon Dis 2016;11:637-648.

5. Limpawattana P, Putraveephong S, Inthasuwan P, Boonsawat W, Theerakulpisut D, Chindaprasirt J. Frailty syndrome in ambulatory patients with COPD. Int J Chron Obstruct Pulmon Dis 2017;12:1193-1198.

6. Choudhury G, Rabinovich R, MacNee W. Comorbidities and systemic effects of chronic obstructive pulmonary disease. Clin Chest Med 2014;35:101-130.

7. Hattiholi J, Gaude GS. Bone mineral density among elderly patients with chronic obstructive pulmonary disease patients in India. Niger Med J 2013;54:295-301.

8. Sakurai-Iesato Y, Kawata N, Tada Y, Iesato K, Matsuura Y, Yahaba M, et al. The Relationship of Bone Mineral Density in Men with Chronic Obstructive Pulmonary Disease Classified According to the Global Initiative for Chronic Obstructive Lung Disease (GOLD) Combined Chronic Obstructive Pulmonary Disease (COPD) Assessment System. Intern Med 2017;56:1781-90.

9. Coin A, Sergi G, Marin S, Vianello A, Perissinotto E, Sarti S, et al. Predictors of low bone mineral density in elderly males 
with chronic obstructive pulmonary disease: the role of body mass index. Aging Male 2010;13:142-7.

10. Hwang DK, Choi HJ. The relationship between low bone mass and metabolic syndrome in Korean women. Osteoporos Int 2010;21:425-31.

11. Graat-Verboom L, Wouters EF, Smeenk FW, van den Borne BE, Lunde R, Spruit MA. Current status of research on osteoporosis in COPD: a systematic review. Eur Respir J 2009;34:209-18.

12. Graat-Verboom L, Spruit MA, van den Borne BE, Smeenk FW, Martens EJ, Lunde R, et al. Correlates of osteoporosis in chronic obstructive pulmonary disease: An underestimated systemic component. Respir Med 2009;103:1143-51.

13. Lehouck A, Boonen S, Decramer M, Janssens W. COPD, bone metabolism, and osteoporosis. Chest 2011;139:648-57.

14. Okazaki R, Watanabe R, Inoue D. Osteoporosis Associated with Chronic Obstructive Pulmonary Disease. J Bone Metab 2016;23:111-120.

15. Hattiholi J, Gaude GS. Prevalence and correlates of osteoporosis in chronic obstructive pulmonary disease patients in India. Lung India 2014;31:221-7.

16. Rittayamai N, Chuaychoo B, Sriwijitkamol A. Prevalence of osteoporosis and osteopenia in Thai COPD patients. J Med Assoc Thai 2012;95:1021-7.

17. Ferguson GT, Calverley PMA, Anderson JA, Jenkins CR, Jones PW, Willits LR, et al. Prevalence and progression of osteoporosis in patients with COPD: results from the TOwards a Revolution in COPD Health study. Chest 2009;136:1456-65.

18. Limpawattana $P$, Inthasuwan $P$, Putraveephong $S$, Boonsawat W, Theerakulpisut D, Sawanyawisuth K. Sarcopenia in chronic obstructive pulmonary disease: a study of prevalence and associated factors in the Southeast Asian population. Chron Respir Dis 2018;15:250-7.

19. Mahler DA, Wells CK. Evaluation of clinical methods for rating dyspnea. Chest 1988;93:580-6.

20. Tu KN, Lie JD, Wan CKV, Cameron M, Austel AG, Nguyen JK, et al. Osteoporosis: a review of treatment options. P T Peer-Rev J Formul Manag 2018;43:92-104.

21. Chen L-K, Liu L-K, Woo J, Assantachai P, Auyeung T-W, Bahyah KS, et al. Sarcopenia in Asia: Consensus report of the Asian working group for sarcopenia. J Am Med Dir Assoc 2014;15.

22. Roberts HC, Denison HJ, Martin HJ, Patel HP, Syddall H, Cooper $\mathrm{C}$, et al. A review of the measurement of grip strength in clinical and epidemiological studies: towards a standardised approach. Age Ageing 2011;40:423-9.

23. ATS Committee on Proficiency Standards for Clinical Pulmonary Function Laboratories. ATS statement: guidelines for the six-minute walk test. Am J Respir Crit Care Med 2002;166:111-7.

24. Jitapunkul S, Kamolratanakul P, Ebrahim S. The meaning of activities of daily living in a Thai elderly population: development of a new index. Age Ageing 1994;23:97-101.
25. Yamamoto Y, Yoshikawa M, Tomoda K, Fujita Y, Yamauchi M, Fukuoka A, et al. Distribution of bone mineral content is associated with body weight and exercise capacity in patients with chronic obstructive pulmonary disease. Respiration 2014;87:158-64.

26. Rundgren A, Eklund S, Jonson R. Bone mineral content in 70- and 75-year-old men and women: an analysis of some anthropometric background factors. Age Ageing 1984;13:613.

27. Nishimura Y, Nakata H, Tsutsumi M, Maeda H, Yokoyama M. Relationship between changes of bone mineral content and twelve-minute walking distance in men with chronic obstructive pulmonary disease: a longitudinal study. Intern Med 1997;36:450-3.

28. Travison TG, Araujo AB, Esche GR, McKinlay JB. The relationship between body composition and bone mineral content: threshold effects in a racially and ethnically diverse group of men. Osteoporos Int 2008;19:29-38.

29. Khwanchuea R, Thanapop S, Samuhasaneeto S, Chartwaingam S, Mukem S. Waist circumference: a key determinant of bone mass in university students. Walailak J Sci Tech 2013;10:65576.

30. Limpawattana P, Kengkijkosol T, Assantachai P, Krairit O, Pimporm J. The performance of obesity screening tools among young Thai adults. J Community Health 2014;39:1216-21.

31. Weaver CM, Gordon CM, Janz KF, Kalkwarf HJ, Lappe JM, Lewis R, et al. The National Osteoporosis Foundation's position statement on peak bone mass development and lifestyle factors: a systematic review and implementation recommendations. Osteoporos Int 2016:1281-1386.

32. Nayyar N, Sood RG, Sarkar M, Tomar A, Thakur V, Bhoil R. Prevalence of osteoporosis and osteopenia in stable patients of chronic obstructive pulmonary disease in Sub-Himalayan region of Himachal Pradesh, India. J Fam Med Prim Care 2017;6:595-9.

33. Kim S, Won CW, Kim BS, Choi HR, Moon MY. The association between the low muscle mass and osteoporosis in elderly Korean people. J Korean Med Sci 2014;29:995-1000.

34. Ischaki E, Papatheodorou G, Gaki E, Papa I, Koulouris N, Loukides S. Body mass and fat-free mass indices in COPD: relation with variables expressing disease severity. Chest 2007;132:164-9.

35. Cauley JA. Defining ethnic and racial differences in osteoporosis and fragility fractures. Clin Orthop 2011;469:1891-9.

This is an open access article distributed under the terms of the Creative Commons Attribution-NonCommercial-ShareAlike 3.0 License, which allows others to remix, tweak, and build upon the work non-commercially, as long as the author is credited and the new creations are licensed under the identical terms

This article was originally published in a special issue, "Biomedical applications in Pharmaceutical Sciences" Indian J Pharm Sci 2020:82(2)Spl issue3;93-100 